\title{
Badging for Accreditation: Electronic Credentialing in the Undergraduate Curriculum
}

\author{
Deserae Gogel, Jannik Haruo Eikenaar, and Parsa Rajabi \\ University of British Columbia | Okanagan Campus \\ deserae.gogel@ubc.ca,jannik.eikenaar@ubc.ca,parsa.rajabi@alumni.ubc.ca
}

\begin{abstract}
We describe the early stages of an innovative initiative to help meet accreditation requirements through co-curricular, electronic credentialing. We describe the electronic credentials, or "digital badges," by giving specific examples from the project and by explaining preparation and delivery. We also share course instructor comments, student feedback, and our own suggestions for best practices going forward.
\end{abstract}

Keywords: badging, electronic credentialing, cocurricular, accreditation

\section{Introduction}

Introduction to Engineering (I2E) is a co-curricular project in UBC's School of Engineering (SoE) that supports the professional development of undergraduate engineering students in their academic work and helps prepare them for the early stages of their careers. Based on feedback from alumni and industry partners, I2E was developed to enhance student learning in areas corresponding to the CEAB graduate attributes of "individual and team work," "communication," "professionalism," "ethics and equity," and "life-long learning." For example, through I2E, students may complete co-curricular modules on critical thinking, leadership and teamwork, information literacy, and psychological safety. The modules are designed within a structure that aligns with the School's approach to accreditation: each module topic is scaffolded at the levels of "introduced," "developed," and "applied."

I2E has recently embraced micro-credentialing, in the form of digital badging, to better differentiate topic levels, define clear learning pathways, make the content more accessible to students, and improve tracking and analysis of student learning. Electronic microcredentialing or "badging" allows students to earn electronic credentials (i.e., "badges") that "[represent] an individual's skills, interests, and achievements" (all4ed.org, 2013). These badges are encoded with metadata that specifies the badge's lifespan and issuer (here, UBC's School of Engineering), provides an overview of the badge itself, and describes the competencies the student has achieved.
As a result, I2E has shifted from the more traditional approach of in-class lecture and assessment to a more flexible, multimodal approach where learning takes place both in the classroom and through the university's Learning Management System (LMS). This allows the inclusion of a wide variety of learning activities and delivery modes, and also allows students to work through the content at their own pace. This approach allows for more flexibility in instruction: prior to the shift to badging, I2E modules were embedded in specific courses and worth course credit. Recognizing completion of modules through badges allows the possibility of students completing them for both course credit and a badge or simply the badge alone.

Even though electronic badging is relatively new to the UBC Okanagan campus, substantial research has been done on the implementation of electronic badging in education. Of this research, there have been several studies that have considered student motivation in the contexts of electronic badging, specifically the benefits of implementing badges in a co-curricular context. Coleman (2018) argues that using badges for cocurricular intervention is an "ideal" method for badge integration because "[co-curricular] badging allows for a rich variety of motivations and opportunities for engagement, while helping students connect their activities and experiences to their learning and development in a meaningful way" (Conclusion, para. 1). Badging as a co-curricular intervention follows from studies that argue for a balance between intrinsic and extrinsic student motivations to enhance student engagement (e.g., McDaniel \& Fanfarelli, 2015; Carey \& Stephaniak, 2018). So although co-curricular intervention means that I2E can make specific connections to accreditation, it is equally beneficial to student learning.

There are several electronic credentialing platforms available for use at Canadian post-secondary institutions. The platform we are using, Badgr, allows integration of learning objectives and student achievements into the badge metadata, and the visual design of the badge communicates the bearer's level of mastery in a given topic. Creating badges that are both "portable [and] stackable" (Badgr, n.d), allows us to map the badges on pathways that users can easily follow. Students benefit from the visibility of the pathways because it makes their learning goals and accomplishments easier to track; employers benefit because they can see how a particular 
badge relates to the bearer's level of competence in a particular area.

\section{Methodology}

Our badging program follows a four-step process: identify the topic area of a specific badge, define the learning outcomes for that badge, develop the content and assessments, and deliver it to students. Here, we use the "Psychological Safety" badge as an example.

\subsection{Identify the topic area}

Following discussion with alumni, industry partners, course instructors, program advisors, and undergraduate students, we identified "Teamwork and Leadership" as a priority area for I2E. In discussions, concerns were consistently raised about healthy teamwork environments, styles of teamwork and leadership, and conflict resolution. This allowed us to further identify sub-topics within the area: "Psychological Safety," "Leadership Styles," and "Preventing and Resolving Conflict." Here, we describe the "Psychological Safety" badge as an example.

The introductory-level module for psychological safety was based on research done by Dr. Amy Edmondson of Harvard Business School, and a study on teamwork by Google, called "Re:Work". We define "psychological safety" as "a group atmosphere where individuals feel safe voicing their opinions or questioning those of their group members." This connects well to graduate attributes of "individual and teamwork" and "ethics and equity," while the reflective portion of the module connects to the attribute of "lifelong learning."

\subsection{Define learning outcomes}

In defining the learning outcomes for each badge, we take into account the specific features of the identified topic and the levels of competence in the accreditation model. Thus, for example, learning outcomes in "Psychological Safety" differ slightly across badge levels, depending on whether it is appropriate to assess students as having achieved "introductory," "developed", or "applied" levels of competence. This differentiation of levels is a good fit with electronic credentialing: as noted by Streater (2018), badging allows students to "demonstrate achievement at key stages throughout their studies" (Uses of digital badges, para. 3). The levels of competence are used to create a learning pathway where the completion of each level is rewarded with an electronic credential, also referred to as a badge. Where possible, we also structure the learning outcomes to be consistent with those of the course in which the badge is delivered.
Many of the learning pathways and objectives for I2E are adapted from the Association for American Colleges and Universities' (AAC\&U) Valid Assessment of Learning in Undergraduate Education (VALUE) rubric. The rubrics have been adapted and extended upon in order to fit the contexts of the engineering program at UBC Okanagan; each rubric reflects the core knowledge, skills, and attributes that are practiced in each module.

The badge for psychological safety was delivered in a First Year engineering design course; therefore, content was created for the "introductory" level. In this module, it is expected that students will:

- explore what psychological safety is and understand how psychological safety is important to effective group work

- begin to identify how psychological safety can be sustained, for self and others, and begin to implement this knowledge in their teams

- create a team contract that incorporates psychological safety

- reflect and revise their team contracts, as per guided feedback and their own experiences as a team

\subsection{Develop content and assessments}

Content and assessments for each badge are developed through literature review and consultation with area-specific experts and our Centre for Teaching and Learning. Once the first modules were complete, we ran student-led focus groups before integrating them into first year classes; the feedback from these groups was invaluable for streamlining content, reinforcing key ideas, and making the module more accessible to students.

For the "Psychological Safety" badge, the main assessments were a team contract and a team contract review. The team contract was a template that prompted students to consider the needs of their group in terms of psychologically safe practice. The team contract review was presented to students a month after making their contracts, and it required teams to reflect on the original terms of their contract in three key stages: what happened, the significance of what happened, and how they would proceed moving forward. Each assignment was marked on a rubric out of three, where they were judged to be at either an "not meeting expectations", "meeting expectations", or "exceeding expectations". To earn the badge in "Psychological Safety" students had to "meet" or "exceed expectations" in both assessments.

\subsection{Deliver to students}

Badge content is delivered via UBC Okanagan's learning management system (LMS), in coordination with Badgr, an online badging platform that allows 
students to "[c]ollect and organize digital badges and credentials" (Badgr, n.d). The LMS allows us to create modules in a digital sandbox that can then be shared with instructors to implement in their specific courses. Modules can include manually and automatically marked assignments, and upon the completion of all required elements, students are directed to retrieve their badges. There is an option for manual (i.e., instructor) badge release, but the auto-release feature allows students to work at their own pace to complete the module, while simultaneously decreasing instructor workload.

Run from September to December in 2019, "Psychological Safety" was among the first modules launched in I2E. The module was co-curricular: students in this First Year design course had already chosen teams, and the main goal of the module was to reinforce psychologically safe team practice. The module content and assessments were delivered online; however, this information was reinforced through two ten-minute presentations, given to students in tutorials. The module was not worth marks in the class. Instead, students were largely motivated by the idea that a contract could reduce team conflict and that earning an electronic badge would benefit them by adding to their resumes or online profiles.

\section{Results and Analysis}

The "Psychological Safety" badge was received positively by students and the course instructor, and we are satisfied with the badge as a pilot in I2E. In a Year One class of 361 students, 168 participated in the initial team contract, and 110 (of those 168) participated in the team contract review. Of those 110,72 passed the assignment at a level sufficient to claim the "Psychological Safety" badge; however, only 21 students actually retrieved their badges in the weeks immediately following completion of the module.

Possible reasons for the low retrieval rate include lack of understanding of how to retrieve the badge; uncertainty about what to do with the badge itself; and lack of interest in using the badge. Student comments on the badge, though, are generally positive. Those who successfully completed the module were invited to provide feedback; this included:

- "I thought that this course was good. The only thing I would suggest is that there is an announcement the day before the assignments are due. For me since I wasn't taking this class weekly it was very forgettable. Other than that I enjoyed the course."

- "I think the structure of the module was well done. The assignment instructions were clear."

- "I feel as if the team contract was beneficial to the cohesiveness of the team and how efficiently we were able to work."
- "The I2E modules set a foundational expectation for the group. It allowed us to work together more efficiently and in a respectful, friendly, and healthy environment. It was also nice to sign the contract so that we act accordingly."

- "Examples on how [to] make an effective contract as well as what it takes to get a $3 / 3$ on the contracts may be useful."

- "We could have had a better feedback [sic] from our submissions and maybe an example of what would be a $100 \%$ work for you. In the end, we did not have an idea of what exactly was good about our contract and what was bad."

This feedback has helped us identify several points for revising the badging module:

- Streamline assignment submission using the LMS's "group" function so that feedback is more accessible to students

- Include content about roles within a team, especially regarding leadership

- Create user guides for both students and instructors that will help further clarify badge retrieval and usefulness

The course instructor was particularly satisfied with the specific content of the badging module for their course, as well as the delivery method. They note that the content is crucial for a Year One, team-based learning project, and they appreciate that the co-curricular structure does not require a great deal of time in class or tutorial (total delivery time averaged about an hour per student).

\section{Discussion}

This is an early stage of our badging program, and we are still exploring how to track and analyze how students use badges, but there seem to be significant benefits to incorporating digital badging in I2E. Among these, electronic badging allows students to immediately demonstrate that they have acquired skills and attributes that connect directly to the graduate attributes outlined by $\mathrm{CEAB}$, rather than waiting for completion of an entire program of study. They also allow instructor flexibility in enhancing course- and program-specific content, without significantly increasing the time required for assessment. Moreover, badging seems viable as a strategy for meeting accreditation requirements, particularly in areas that are historically challenging to instruct, assess, and report: for example, life-long learning and professionalism. In the short term, then, badging can function as a highly visible and very flexible supplementary curricular intervention, and in the longer term it has potential to be embedded within curricula.

Our next steps are to review and revise the badges we have already delivered, monitor delivery of our next 
group of badges, and create badging user guides for both students and instructors. We plan to assess badging as a strategy for accreditation by collecting and analyzing instructor and student feedback, through surveys and focus groups. At the time of writing, we are delivering several other badges, including "Information Literacy," "Leadership Styles", and "Collaboration," and we are developing two others in conjunction with other academic units: these are "Indigenous Foundations" and "Intercultural Foundations." Although electronic badging is relatively new to the UBC Okanagan, there has been a growing enthusiasm to see it implemented both in and outside of the School of Engineering.

\section{Acknowledgements}

We acknowledge that funding for I2E has been provided by the Aspire Learning and Teaching (ALT) fund at the Okanagan campus of UBC.

In addition, we thank Dr. Ray Taheri for hosting the "Psychological Safety" badge in his course, and for providing feedback and guidance to make sure it was a good co-curricular fit. Finally, we thank Mehnaz Tabassum and Kyla Morris for their help in proof-reading module content and marking assignments.

\section{References}

All4ed.org (2013). Expanding education and workforce opportunities through digital badges.

Fanfarelli, J.R. \& McDaniel, R. (2019). Designing Effective Badges: Applications for Learning. New York, NY. Routledge.

Badgr. (n.d.) Retrieved January 15, 2020, from: https://info.badgr.com/

Carey, K.L., Stefaniak, J.E. An exploration of the utility of digital badging in higher education settings. Education Tech Research Dev 66, 1211-1229 (2018). https://doiorg.ezproxy.library.ubc.ca/10.1007/s11423-018-9602-1

Coleman, J.D. Engaging undergraduate students in a cocurricular digital badging platform. Educ Inf Technol 23, 211-224 (2018).

https://doi-org.ezproxy.library.ubc.ca/10.1007/s10639017-9595-0

Edmondson, A. C., \& O'Reilly for Higher Education. (2019;2018). The fearless organization: Creating psychological safety in the workplace for learning, innovation, and growth. Hoboken, New Jersey: John Wiley \& Sons, Inc.

re:Work. (n.d.). Tool: Foster Psychological Safety. Retrieved August 1, 2019 from https://rework.withgoogle.com/guides/understandingteam-effectiveness/steps/foster-psychological-safety/

Shaw, F. et al. (2018). Educational functions and design of badge systems: A conceptual literature review. IEEE Transactions on Learning Technologies 11 (4): 536-544. Doi: 10.1109/TLT.2017.2773508

Streater, K. Digital Badging the Future of Professional Development. ITNOW, 60(2), Summer 2018, pp. 56-57, https://doi-

org.ezproxy.library.ubc.ca/10.1093/itnow/bwy056

\section{Appendix A: Teamwork and Leadership Rubric / Psychological Safety Learning Outcomes}

As mentioned, the rubric for tracing learning outcomes and pathways was adapted from the $A A C \& U$ VALUE rubric in critical thinking. Key additions include adding the course codes where modules would be implemented and the corresponding graduate attribute indicators that the module would target. Learning objectives were initially drafted by considering the connections between the topic (i.e. psychological safety) and relevant graduate attributes. It was also important that learning objectives are based on key knowledge, skills, and attitudes that students demonstrate over the course of the module. Although the rubric was drafted by the end of August, it is a living document, changing subtly to fit the needs of the course instructor when a module is assigned to a course.

All of this information is available to students from the start of the module so connections to graduate attributes and the associated learning objectives are clear from the start. In addition, learning objectives are included on each of the respective assignments, allowing students to see how and where they are accomplishing each objective. Completed assignments can be connected to the metadata of the final badge; however, we opted not to use this feature as it complicates the retrieval process for students, who are already unfamiliar with the process.

Table 1: Teamwork and leadership rubric for Psychological Safety

\begin{tabular}{|l|l|}
\hline $\begin{array}{l}\text { Leadership } \\
\text { and }\end{array}$ & $\begin{array}{l}\text { 4. Psychological Safety } \\
\text { Teamwork } \\
\text { Modules }\end{array}$ \\
& $\begin{array}{l}\text { Edmondson. Understanding that } \\
\text { psychological safety is important for } \\
\text { people to accomplish their best } \\
\text { work; recognizing what is and is not } \\
\text { psychologically safe practice in a } \\
\text { team setting. }\end{array}$ \\
\hline
\end{tabular}

CEEA-ACEG20; Paper 62

Concordia and McGill Universities; June 18-21, 2020-4 of 6 - 


\begin{tabular}{|c|c|}
\hline $\begin{array}{l}\text { Course } \\
\text { Codes }\end{array}$ & APSC 171 (T1) \\
\hline $\begin{array}{l}\text { GA } \\
\text { Indicators }\end{array}$ & $\begin{array}{l}6.2 \\
10.1 \\
10.2 \\
12.1\end{array}$ \\
\hline $\begin{array}{l}\text { Learning } \\
\text { Objectives: } \\
\text { Introduced } \\
\text { (Year 1) }\end{array}$ & $\begin{array}{l}\text { Learners will: } \\
\text { a) explore what psychological safety } \\
\text { is and understand how psychological } \\
\text { safety is important to effective group } \\
\text { work } \\
\text { b) begin to identify how } \\
\text { psychological safety can be } \\
\text { sustained, for self and others, and } \\
\text { begin to implement this knowledge } \\
\text { in their teams } \\
\text { c) create a team contract that } \\
\text { incorporates psychological safety } \\
\text { d) reflect and revise their team } \\
\text { contracts, as per guided feedback and } \\
\text { their own experiences as a team }\end{array}$ \\
\hline
\end{tabular}

The "Learning Objectives," as seen in Table 1, transpose into part of the metadata used to encode the badge (see Fig. 2). Other important elements of the badge include detailed information about the issuer, the visual identity of the badge, and tags that provide connections to other relevant material and/or badges.

Fig. 2. Metadata for badge in Psychological Safety

\section{Appendix B: Badging Pathways}

Using UBC Okanagan's relatively new Learning Management System (LMS), Badgr was set up as an external application on I2E's LMS shell. Through this system, Badgr's settings were configured to meet UBC's privacy policies while also allowing $\mathrm{I} 2 \mathrm{E}$ to create and issue badges for students in the School of Engineering.

The LMS allows instructors to create modules within course shells, and students are able to interact with the content and mark each page as done after they have read and completed all the elements on the page. Through the use of LMS elements such as pages, quizzes and assignments, instructors are able to teach, assess and track students' progress throughout the module. By using the LMS module settings, instructors are able to add requirements to each module such as: viewing a page, marking a page as done, submitting an assignment or obtaining a certain grade on a quiz. After a student has completed all the requirements of a module, that status of

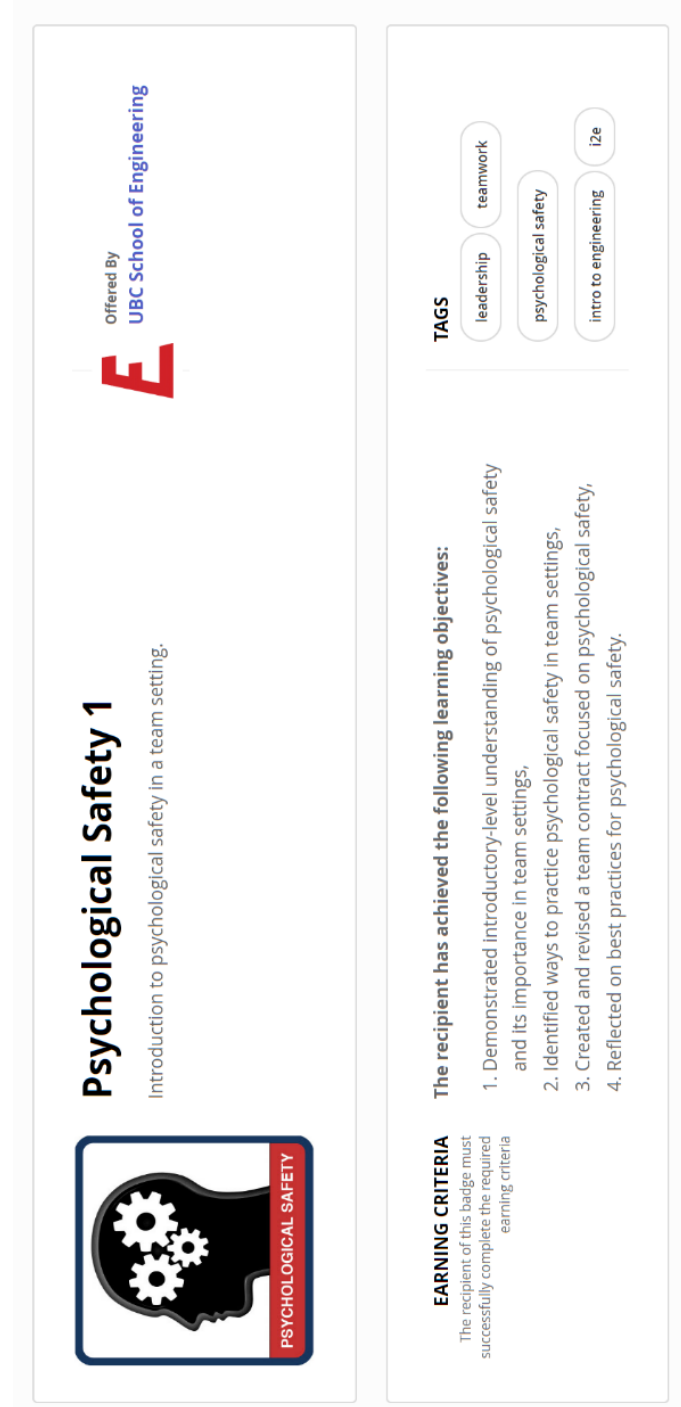

the module changes to completed. The Badgr system uses the module status to consistently check if a student has completed a module or not and based on the status, the Badgr system will automatically issue the pre-assigned badge to that students who completed the module.

To prepare for the system to auto issue badges to students, the badge must be created in advance alongside its associated metadata. The metadata is unique to each badge as it is used to identify and track each badge throughout the system. Some of the elementary data related to the badge badge's metadata includes, badge image, name, short description, and earning criteria. In addition, there are more advanced optional metadata such as alignment information with educational standards, tags and an expiration date for the badge. The metadata for the badge can be viewed by students and 3rd party associates by simply clicking on the badge and viewing it on the Badgr.io website.

CEEA-ACEG20; Paper 62

Concordia and McGill Universities; June 18-21, 2020 - 5 of 6 - 
In addition to creating a badge, each badge must be placed within its respective pathway. A pathway can be described as a route that students take to build on their existing knowledge while also advancing towards a more robust badge. For example, the Psychological Safety badge is part of the Leadership and Teamwork pathway. Through this pathway, students are able to visually identify where in the pathway they currently are and what the next sequential badge is. Furthermore, after completing the introductory badge, all future badges will enforce a prerequisite badge to ensure the students follow sequential order when completing their badges. For example, the Psychological Safety (Developed) badge has a prerequisite of Psychological Safety (Introduced), which can visually be identified on the left hand side of the pathway builder (labeled in blue in figure 1) and once the student completes the module, they will then earn the Psychological Safety (Developed) badge found on the right hand side of the pathway builder (labeled in purple in figure 1).

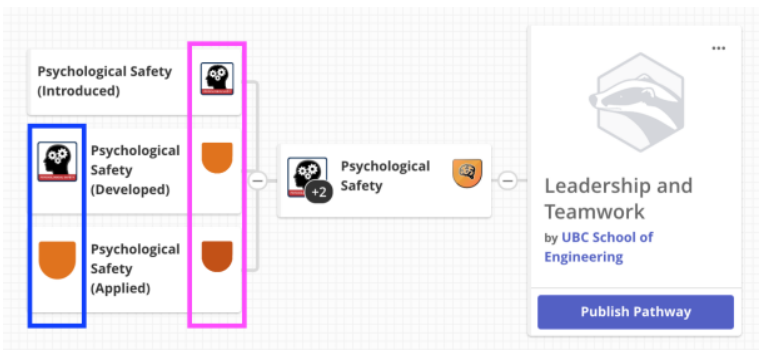

Fig. 3. Leadership and teamwork pathway - Psychological Safety

While digital badging is still in its early stage of development, the integration of Badgr and the LMS has made it possible to create and monitor these badges and pathways for both students and instructors. Some features such as Badgr's Learning Tools Interoperability (LTI) are key to continuing on with digital badging as the feature would allow the badge issuer to monitor and update pathways automatically without needing to manually import or export items within the LMS. By using a keypair authentication, the Badgr system would be directly linked to the customer's LMS and allow for seamless creation of new badges and pathways while also allowing the badge issuer to update any existing badges and pathways within their system. 